\title{
Experimental Models of Renal Disease and the Cardiovascular System
}

\author{
Rebecca C. Grossman* \\ Department of Cellular Pathology, Royal Free Hospital, London NW3 2QG, London, United Kingdom
}

\begin{abstract}
Cardiovascular disease is a leading cause of death among patients with end stage renal failure. Animal models have played a crucial role in teasing apart the complex pathological processes involved. This review discusses the principles of using animal models, the history of their use in the study of renal hypertension, the controversies arising from experimental models of non-hypertensive uraemic cardiomyopathy and the lessons learned from these models, and highlights important areas of future research in this field, including de novo cardiomyopathy secondary to renal transplantation.
\end{abstract}

Keywords: Non-hypertensive uraemic, de novo cardiomyopathy, renal transplantation, karyotypes, isoform.

\section{INTRODUCTION}

Animal models have been invaluable in the study of human disease. In addition to the anatomical and histological characteristics humans share with other species, human diseases can be reproduced in these species using pharmacological, surgical or genetic manipulation. Experimentation still provides the best evidence for disease causation, and only with this evidence can clinical science proceed to developing treatments. However, experimentation is often not possible or ethical in human subjects, and thus without these animal models the advancement in knowledge of the pathophysiology of disease would come to a standstill.

In few other specialities have experimental models been as crucial to the study of pathology as in renal medicine. The way in which kidneys succumb to disease and the development of renal failure involves complex interactions between numerous different systems, mediated by a multitude of chemicals. Current understanding of renal disease is merely the tip of the metaphorical iceberg. The history of renal pathology is plagued by controversy, and nowhere is this more evident than in the development of cardiovascular disease in patients with chronic renal failure. Impairment of renal function increases the risk of cardiac disease to 15-20 times that of individuals with normal renal function $[1,2]$. The result is that cardiac disease causes $40 \%$ of deaths in patients on dialysis [3]. From the Goldblatt kidney to modern molecular studies, this review focuses on the use of experimental models in the study of the relationship between renal and cardiovascular disease, and highlights the questions that remain unanswered.

\section{CHOOSING AN ANIMAL MODEL}

It is not possible to perform a systematic review of all the papers published on animal models in renal and

*Address correspondence to this author at the Department of Cellular Pathology, Royal Free Hospital, Pond Street, London NW3 2QG, United Kingdom; Tel: 0207794 0500; Fax: 0207830 2468;

E-mail: rebeccagrossman@doctors.org.uk cardiovascular disease, as the area is extremely broad. The aim of this review is, therefore, to summarise the key methods in the study of renal disease, and highlight what has been learned from animal models on the subject of renal disease and the cardiovascular system, focusing on the key experiments.

That said, following on from the estimates by Pinto et al. [4] of the number of publications on hypertension per species, a search was performed on Pubmed for "renal and cardiovascular disease model" for various species, in order to gain some insight into which animals are most commonly used in this field, bearing in the mind the crudeness of such a search, as previously emphasised [4]. The results are shown in Table $\mathbf{1}$.

Table 1. Publications on Animal Models of Renal and Cardiovascular Disease

\begin{tabular}{|l|c|}
\hline Species & Number of References (No Date Limits) \\
\hline \hline Rat & 1830 \\
\hline Mouse & 416 \\
\hline Pig & 325 \\
\hline Dog & 275 \\
\hline Rabbit & 173 \\
\hline Cat & 28 \\
\hline Baboon & 15 \\
\hline Cattle & 15 \\
\hline Guinea pig & 12 \\
\hline Hamster & 10 \\
\hline
\end{tabular}

(Source: Pubmed 16 November 2009).

Many different animals have been used to replicate human disease, and the selected species depends on what is 
required from the experiment. Choosing the animal model is a process in which cost, animal welfare and practical suitability must all be considered. All species have both advantages and disadvantages with regards to this process.

An ideal animal model should have similar anatomy and physiology to humans; results of experimentation should be readily transferable to humans; similar pathological findings to humans should be evident; and interventions to reproduce human pathological findings in the animal should be technically achievable without producing pain or suffering.

\section{Rat Models}

As can be seen from Table 1, the rat is the most commonly used model in the study of renal and cardiovascular disease. Types include Wistar, Sprague-Dawley, Fawnhooded, Fisher and Lewis. The advantages of using rat models are that they are inexpensive and have short gestation periods (59-72 days) [5], meaning large sample sizes can be achieved in a short space of time [6]. The disadvantages are predominantly due to the anatomical, physiological and pathological differences between rat and man. With respect to cardiac physiology, rat myocardium has a shorter action potential and the sodium calcium pump $\left(\mathrm{Na}^{+} / \mathrm{Ca}^{2+}\right.$ pump) has a smaller role [6]. Furthermore, the myosin isoforms are different, heart rates are faster, and the force-frequency relationship is inversed. Doggrell and Brown highlight some of the important pathological differences between rat and man relating to cardiovascular disease: that these diseases are slowly developing in man, compared to the rapid onset imposed upon laboratory rats; and that these diseases are more common in older humans, but laboratory rats are usually young [7]. In addition, atherosclerosis is seldom seen in rats [4], whereas this process plays an important role in human cardiovascular disease.

\section{Mouse Models}

The mouse is the most commonly used animal in laboratory research in general [5]. Mouse models share similar advantages to rats, with the addition that the karyotypes of the many inbred strains and outbred stocks are known, making it useful for genetic modification, such as gene knockout models. However, mice are smaller than rats, making surgical interventions more technically difficult.

\section{Rabbit Models}

Rabbits are larger than rats and mice and less expensive than dogs and pigs, and share certain cardiac physiological features with humans: rabbit hearts have a predominant betamyosin heavy chain isoform [6], and a similar sarcoplasmic reticulum and force-frequency relationship to humans.

\section{Large Animal Models}

Large animals such as dogs and pigs are used to study cardiac function and ventricular volumes with greater accuracy than would be achieved in smaller animals [6], and allow long-term interventional measures to be used to produce physiological changes. Dogs are particularly useful as the cardiac electrophysiology is similar to humans, with dominance of the beta-myosin heavy chain isoform as in rabbits. Pigs also have similar anatomy and physiology to humans. The disadvantages of using large animals are primarily cost, long gestation and growth times, and the extensive resources required to provide adequate care.

\section{RENAL HYPERTENSION: THE GOLDBLATT KIDNEY AND BEYOND}

Hypertension has a complex, multifactorial aetiology, the study of which is further complicated by the arbitrary cut-off that separates the pathological from the norm. The most common type of this condition is so-called essential hypertension, which probably represents an interplay of various genes, via their diverse alleles and levels of penetrance. Often these facts are taken for granted, and what is less commonly considered is the controversy that mars the history of hypertension research, which centres on the relationship between hypertension and the kidney. There are several informative reviews written on the subject of animal models in hypertension [4, 8], including the use of endocrinological, metabolic, diet-induced, salt-induced and genetic models of essential hypertension, as well as the spontaneously hypertensive rat. This section will thus briefly review the history of the use of experimental models in renal hypertension, as the methods and theories learned from these experiments have contributed greatly to the work performed on nonhypertensive renal causes of cardiovascular disease.

Harry Goldblatt (1891-1977), born and educated in Canada, was a Professor of Experimental Pathology at the Western Reserve University School of Medicine in Cleveland, Ohio [9, 10]. Throughout his career, he had been interested in the role of the kidney in the development of hypertension, and it was his work that led to the use of the eponymous Goldblatt kidney. The studies of Goldblatt and his colleagues on experimental hypertension from 1934 onwards, were a landmark series of experiments that paved the way for future methods of inducing persistent hypertension in laboratory animals [11-14]. In the first of these experiments, the authors used a clamp to constrict the renal arteries of dogs, producing renal ischaemia and rendering the dogs hypertensive for several months [11]. Unilateral renal ischaemia produced hypertension which was transient, partly due to the development of a collateral circulation to the affected kidney which restored blood flow. Bilateral moderate constriction of renal arteries produced hypertension with no renal dysfunction, while nearly complete bilateral constriction resulted in very high blood pressures and severe renal dysfunction. Another method of producing persistent hypertension was to constrict one renal artery, and once the blood pressure was elevated, to remove the contralateral kidney. Goldblatt et al. also showed that hypertension could arise from constriction of the suprarenal aorta [13]. Goldblatt subsequently showed that in other animals, including monkeys, sheep, rabbits and rats, constriction of one renal artery was sufficient to produce hypertension lasting many months [12, 14-16].

The clamps used by Goldblatt et al. subsequently evolved into clips, with Pickering and Prinzmetal using a silver clip to constrict rabbit arteries [17]. These silver clips were used by Wilson and Byrom on rats to study accelerated (malignant) hypertension [18]. It was later shown that changing the clip diameter could produce different degrees of hypertension in the Wistar rat [19], and that the onset of hypertension could be gradual and chronic, with a plateau at two weeks. In a small number of rats, blood pressure may subsequently 
decrease [8]. These methods continue to be used; Capasso et al. applied a unilateral silver clip to the renal arteries of Fischer rats to study hypertensive left ventricular failure [20]. To study cardiac remodelling, Brilla et al. used a modified two-kidney, one-clip model by subjecting SpragueDawley rats to abdominal aortic banding with unilateral renal artery constriction, producing unilateral renal atrophy [21]. Dobrian et al. used the one-kidney, one-clip method in Wistar rats, and uninephrectomised rats as normotensive controls, to show that blood pressure could be well controlled with the synergistic use of an angiotensin II blocker and a superoxide dismutase mimetic [22]. Both the twokidney, one clip method [23, 24] and the one-kidney, oneclip [24] methods have also been successfully used in mice.

The two-kidney, two-clip and one-kidney, one-clip models are volume-dependent models of hypertension [7, 8], with the former the animal equivalent of bilateral renal artery stenosis in humans. It has been shown to be less dependent on the activation of the renin-angiotensin system (RAS) than the two-kidney, one-clip model. The latter is a pressure overload model, and dependent on activation of the RAS and vasoconstriction [7]. It is therefore sensitive to antagonists of the RAS. It is also sensitive to changes in dietary sodium, with a high sodium intake augmenting hypertension, and restriction of sodium reducing it [8]. It responds to calcium antagonists and vasodilators, but not to diuretics, betablockers and endothelin antagonists [4].

Unilateral renal artery stenosis has been used in pigs to study oxidative stress in renovascular hypertension [25]. Stenosis was produced by inserting a local-irritant coil into the renal artery, which resulted in a gradual proliferative neointimal response and progressive luminal narrowing. The authors demonstrated that a moderate stenosis produced only a transient increase in RAS activity, with oxidative stress remaining active.

There have also been experimental models that did not depend on renal artery constriction. Page produced the "perinephritis-type" hypertension by wrapping kidneys in silk and cellophane, resulting in the growth of a capsule of connective tissue, with compression of the renal parenchyma and subsequent ischaemia [26]. This was applied to dogs, cats, rabbits and cynomolgus monkeys [8], and has been shown to be dependent on the RAS and on endothelin-1. The method used by Grollman is similar; it is a two-kidney, oneFigure-8 wrap model [27], which has been used to study angiotensin in Sprague-Dawley rats [28]. The renal wrapping method has also been used in dogs to study diastolic heart failure [29].

Finally, the reduced renal mass method has been used less often to study renal hypertension; in this process $75 \%$ of the renal tissue is removed [30]. Nephrectomy models are more commonly used to study non-hypertensive cardiovascular disease in renal impairment. This model has been used in combination with a high salt diet, for example, to study the regulatory role of substance $P$ in Sprague-Dawley rats [31].

\section{URAEMIC CARDIOMYOPATHY: AN EXAMPLE OF LESSONS LEARNED}

The subject of a uraemic cardiomyopathy occurring independently of hypertension and thus of afterload has been a contentious one. Clearly, chronic renal disease and atherosclerotic cardiovascular disease share certain risk factors, such as diabetes and hypercholesterolaemia. Yet coronary artery disease only accounts for half of the cardiac mortality of patients with end-stage renal failure [1]. Uraemic patients often die of congestive cardiac failure, sudden cardiac death, or uraemic cardiomyopathy. The cardiac findings associated with uraemia comprise of predominantly left ventricular hypertrophy, as well as, left ventricular dilatation and systolic dysfunction [32]. A similar fibrosis is not seen in other organs of animals with chronic renal failure.

Due to the controversy surrounding uraemic cardiomyopathy, a multitude of papers have been devoted to using animal models in the study of this condition. Most of these experiments have used the 5/6 nephrectomy model, in which the rat is anaesthetised and one kidney is removed. After an interval of 1-2 weeks, $2 / 3$ of the contralateral kidney is destroyed either by actual removal of renal tissue, or by infarction via ligation of two or three branches of its renal artery $[33,34]$.

Perez-Ruiz et al. highlighted a forgotten technique to study uraemic cardiomyopathy [35]. This method involves tying off the renal parenchyma in both renal poles. The authors claim that this method shares the advantages of the nephrectomy model, such as the reproducibility and homogeneity, while avoiding excessive bleeding, an advantage seen in the infarction technique.

Non-interventional studies of the heart in chronic renal failure have been performed, using the normotensive Zucker obese rat. This animal develops renal failure secondary to structural abnormalities, obesity and glucose intolerance, but not diabetes or hypertension. This allowed the study of a non-surgical uraemic cardiomyopathy; indeed, left ventricular hypertrophy was evident at 13 months [36].

\section{Changes in Uraemia: Myocardial Hypertrophy}

According to Rambausek et al. [37], the first recorded increase in heart weight secondary to experimental renal failure was in 1879 [38]. However it was the study by Rambausek et al. of subtotally nephrectomised SpragueDawley rats that provided the first clear insight into the independence of this process of blood pressure [37]. In their experiments, they found an increase in dry, de-fatted heart weight in the experimental group (after a range of 14-21 days of uraemia) compared to controls (sham operated rats), despite beta adrenoceptor blockade, alpha-1 adrenoceptor blockade, and pharmacological normalisation of blood pressure with hydralazine or furosemide. The authors also demonstrated a shift from V3 to V1 isomyosin (with a faster contractile response) in the experimental group, which correlated with creatinine levels.

These results were reproducible, and experimental evidence of myocardial hypertrophy secondary to chronic renal failure has subsequently become abundant [39]. There has continued to be some contention regarding the role of blood pressure in uraemic cardiomyopathy. Fabris et al. demonstrated that the left ventricular weight of 5/6 nephrectomised Wistar hypertensive rats given only drinking water was greater than in rats given lisinopril, which were subsequently normotensive [33]. Although the correlation they showed 
between blood pressure and the degree of ventricular hypertrophy is intriguing, the limitations of this study were considerable: there were no sham-operated controls; the weights measured were of wet, freshly dissected hearts; and angiotensin converting enzyme (ACE) inhibitors have complex effects on cardiac morphology, not merely acting via their antihypertensive effects. Clearly, blood pressure control is important in preventing cardiovascular disease in patients with chronic renal impairment, but the authors themselves acknowledged that there are other mechanisms at play.

\section{Myocardial Interstitial Fibrosis, Cardiac Compliance and Vascular Architecture}

Using subtotally nephrectomised Sprague-Dawley rats, Mall et al. [40] showed that the increase in total heart weight demonstrated by Rambausek et al. [37] after 21 days of uraemia (as well as an increase in both right and left ventricular weight) was secondary to an increase in true interstitial volume, both cellular and non-cellular, with increased deposition of collagen. This was associated with activated interstitial cells, and a reduced capillary cross-sectional area. In 1992, this latter point was confirmed using stereological techniques to analyse perfusion-fixed hearts of subtotally nephrectomised Sprague-Dawley rats [41]. Uraemia resulted in increased blood pressure and reduced capillary length per unit myocardial volume, as well as reduced capillary luminal surface density and volume density, compared to control rats. The same group found a blood pressure-independent increase in the wall to lumen ratio of intramyocardial arteries, and in the aorta media thickness of subtotally nephrectomised rats [42]. The intramyocardial arterial wall thickening has been found to be due to hypertrophy rather than hyperplasia, independent of blood pressure [43].

These architectural changes were reported again in 1996 [44]. In that experiment, nephrectomised Sprague-Dawley rats were given ramipril, nifedipine or moxonidine to normalise blood pressure; these drugs had differential effects on the above architectural changes, and also acted to prevent these changes.

The different changes in interstitial and capillary density in uraemic cardiomyopathy have not yet been explained, but the role of growth factors such as basic fibroblast growth factor (BFGF) and vascular endothelial growth factor (VEGF) has been proposed [44]. The reduced capillarisation was not seen in skeletal muscle (psoas) of nephrectomised rats [45], although blood pressure was not corrected in the experiment.

The above findings [40] were not seen when one-clip, two-kidney rat models of renovascular hypertension were studied. It was suggested that the consequences of the fibrosis produced in the nephrectomised rats would equate to direct, negative effects on cardiac compliance in uraemic patients, as well as resulting in altered electrical excitation pathways, a potential cause of the sudden cardiac death so often seen in renal patients. The electrophysiology of uraemic rats, both of isolated myocytes and the whole left ventricle, was later studied using a whole-cell patchclamp by Donohoe et al. [46], who found altered cardiac transient outward $\mathrm{K}^{+}$current resulting in shorter action potentials.

\section{Reduced Cardiac Chronotropic and Inotropic Respon- siveness in Uraemia}

To study cardiac function in uraemia, bilaterally nephrectomised rats have been treated with ACE inhibitors, muscarinic antagonists and ganglionic blockers [47], and challenged with intravenous isoprenaline. Uraemic rats showed a lower maximal response in heart rate, but no difference in blood pressure. Intravenous forskolin led to a lower maximal response in heart rate in the experimental rats, independent of receptor activity. This was attributed to reduced adenylate cyclase activity. Similarly, reduced cardiac beta-adrenoceptor responsiveness was demonstrated in uraemic Wistar rats [48]. This time the inotropic responsiveness was due to reduced isoprenaline-induced activation of adenylate cyclase, potentially by uncoupling or inhibition; muscarinic receptor function was unaltered.

\section{Cardiac Function and Energetics in Uraemia}

The above experiments provided some insight into the structural changes seen in uraemic hearts. They were followed by a study using the subtotal (5/6) nephrectomy model on Wistar rats, in which the authors focused on the mechanical effects of these structural changes in vitro, thereby removing neurohormonal influences on cardiac contractility [3]. Four weeks after surgery, isolated perfusing working heart preparations demonstrated reduced cardiac output. However, blood pressure was not controlled during the four weeks post-operatively, and could have contributed to the effects. An increased susceptibility to ischaemic damage was also shown via decreased phosphocreatine content, and an increased release of inosine (a marker of ischaemic damage). These hearts failed in response to increases in calcium; the authors proposed that impaired cytosolic calcium control played a role in the relationship between renal failure and impaired cardiac function.

This in vitro experiment demonstrated the fact that impaired cardiac function was independent of circulating urea and creatinine, as the hearts were perfused with physiological saline, with no effect from the addition of urea and creatinine. The opposite has been shown in spontaneously beating mouse cardiac myocytes [49], in response to sera from patients on haemodialysis for chronic renal failure. Urea, creatinine, and combinations of the two reduced the cardiac inotropy and resulted in arrhythmias and asynchronies.

Using subtotally nephrectomised Sprague-Dawley rats, Reddy et al. demonstrated that early experimental uraemia was associated with cardiac hypertrophy with normal function, and normal myocardial carnitine levels in the presence of serum carnitine deficiency [50]. As carnitine plays an important role in myocardial energy metabolism, they postulated that tissue carnitine stores served to maintain cardiac metabolism in early uraemia.

These experiments make a good case for uraemic cardiomyopathy to be a distinct entity from hypertensive cardiac dysfunction and atherosclerotic cardiac disease secondary to the risk factors common to both heart and kidney disease. The cause of this phenomenon is still controversial, with parathyroid hormone (PTH), angiotensin II, marinobufagenin (MBG), oxidative stress, and growth hormone 
(GH) all having been put forward as likely contributors to the process.

\section{The Role of Calcium in Uraemic Cardiomyopathy}

Calcium ions play a crucial role in cardiac physiology, particularly in myocardial excitation-contraction coupling [51]. Therefore, PTH was one of the first culprits to be suspected of playing a role in the pathophysiology of uraemic cardiomyopathy; this was as early as 1984 [52].

As reviewed by Rostand and Drüeke [51], there are numerous theories pertaining to the mechanisms whereby PTH could act as an intermediary between renal impairment and cardiomyopathy. These include direct trophic effects on myocytes and interstitial fibroblasts, and indirect effects via anaemia or large and small vessel changes. Rostand and Drüeke suggest an increase in blood pressure via hypercalcaemia, but the effects on the heart appear to be independent of blood pressure [42].

Rambausek et al. [37] noted increased cardiac calcium content in experimental rats, and that an increase in heart weight still occurred after parathyroidectomy with calcium supplementation. This was followed in the 1990s by in vitro experiments that demonstrated; an increased cytosolic calcium concentration in isolated rat myocytes in response to PTH [53], a reduced expression of PTH-related peptide receptor mRNA in rat hearts secondary to hyperparathyroidism due to chronic renal failure [54], and increased force and frequency of contraction of isolated, beating rat cardiomyocytes $[51,55]$.

Subsequent to "chance observations" in the laboratory, Amann et al. [56-58] argued for the role of PTH in the wall thickening of intramyocardial arterioles and for fibroblast activation and subsequent cardiac fibrosis. Through the use of subtotal nephrectomy, parathyroidectomy and calcimimetics in rats, they were able to control the doses of PTH received (though they did not measure the serum PTH). Abolishing hyperparathyroidism using these methods prevented the cardiac fibrosis and capillary changes normally seen in nephrectomised rats, which was independent of blood pressure.

This hypothesis has already been taken from the bench to the bedside, such as in the large retrospective study of haemodialysis patients in the USA, which found higher rates of cardiovascular events and death in association with disorders of bone mineral metabolism, in particular with high phosphorus and calcium-phosphorus levels [59].

\section{The Renin-Angiotensin System (RAS) and Endothelin}

Many studies have highlighted the importance of the RAS in the development of uraemic cardiomyopathy [33, 34, 44, 60]. Tornig et al. [44] showed that in nephrectomised rats, ramipril, an ACE inhibitor, prevented the increased wall thickness of the intramyocardial arterioles, as well as the expansion of nonvascular cardiac interstitial volume and the aortic wall and lumen changes, but not the reduced capillary length density. The same group subsequently repeated these observations, and demonstrated that the beneficial effects of ramipril were prevented by the use of specific bradykinin B2 receptor antagonists, suggesting a role for increased bradykinin as a mediator for the effects of ramipril [34].
Studies on mesenteric vessels from uraemic SpragueDawley rats showed significant intimal cell proliferation and intimal thickening in resistance vessels in low-flow conditions, with a reduction of these effects by an endothelin receptor antagonist [61]. These antagonists were also shown to prevent the interstitial changes of cardiac fibrosis [62].

The hypertrophy-sparing effects of angiotensin II receptor blockade were also seen in subtotally nephrectomised Wistar rats by a Japanese group, who suggested that protein kinase $\mathrm{C}$ (PKC) and extracellular signal regulated kinase (ERK) activation were involved in the hypertrophy process [63]. They also showed that pitavastatin caused a reduction in angiotensin II-induced ERK activation and prevented the development of hypertrophy, without any change in blood pressure [64].

\section{Oxidative Stress}

The role of oxidative stress and nitric oxide (NO), proposed as a putative pathogenic mechanism for uraemic cardiomyopathy in as early as the 1990s [42, 65], was further investigated by Kalk et al. [66]. They used an NOindependent activator of soluble guanylate cyclase in 5/6 nephrectomised rats to demonstrate a reduction in cardiac hypertrophy and arterial wall thickness, with a concomitant reduction in blood pressure and renal disease progression. Michea et al. [67] have shown increased superoxide production in $5 / 6$ nephrectomised Sprague-Dawley rats, which is prevented by the administration of spironolactone, a mineralocorticoid receptor antagonist. Upregulation of the prooxidant pathway in 5/6 nephrectomised rats has also been reversed by exercise on running wheels [68].

\section{Growth Hormone (GH)}

The effect of GH on the heart was studied in 5/6 nephrectomised Sprague-Dawley rats [69]. Low dose GH was found to prevent the reduced capillary length density and increased fibroblast volume density, with reduced collagen and transforming growth factor-beta (TGF-beta); aortic abnormalities were not affected. High-dose GH was found to worsen uraemic cardiomyopathy.

\section{The Role of Cardiotonic Steroids}

A group from the University of Toledo postulated a role for digitalis-like substances, or cardiotonic steroids, in the pathogenesis of uraemic cardiomyopathy, in particular MBG [70], via the plasmalemmal sodium potassium ATPase $\left(\mathrm{Na}^{+} / \mathrm{K}^{+}\right.$-ATPase). Subtotally nephrectomised SpragueDawley rats were immunised against MBG, while shamoperated received MBG infusions. These infusions resulted in cardiac fibrosis, oxidative stress, and reduced expression of the cardiac sarcoplasmic reticulum ATPase, whereas, immunisation against MBG produced the reverse effect. This was followed by in vitro studies showing that MBG stimulates fibroblast collagen production, accounting for the cardiac fibrosis [71].

\section{The Sodium Potassium ATPase $\left(\mathrm{Na}^{+} / \mathrm{K}^{+}\right.$-ATPase $)$}

Previous studies have mostly used the method of renal decapsulation as sham-operated controls. Kennedy et al. [72] compared Sprague-Dawley rats that underwent 5/6 nephrec- 
tomy to rats that underwent suprarenal aortic banding. Both experimental groups developed hypertension to the same extent, but the nephrectomised rats developed greater cardiac hypertrophy. The nephrectomised rats also exhibited downregulation of cardiac $\mathrm{Na}^{+} / \mathrm{K}^{+}$-ATPase, impaired myocyte contractile function, and abnormal cell calcium cycling. The effect of uraemia on the $\mathrm{Na}^{+} / \mathrm{K}^{+}$-ATPase pump has been variable in different experiments, leaving the role of this molecule uncertain. Kennedy et al. suggest that both systolic function and diastolic function are abnormal, but that the systolic function is normal in vivo because it is masked by circulating digitalis-like substances in uraemia.

\section{Animal Models in Uraemic Cardiomyopathy}

Nearly all the animal models of uraemic cardiomyopathy have involved the use of rats. However, Kennedy et al. performed a 5/6 nephrectomy on CD1 mice, resulting in hypertension, cardiac enlargement and fibrosis, similar to the rat models [73]. As the karyotype of the mouse is well known, this murine model offers opportunities for the use of genetic manipulation in the study of uraemic cardiomyopathy. Indeed, the same group have already taken this opportunity [74], by studying mice with knockdown of Friend leukaemia integration-1 transcription factor (Fli-1) subject to 5/6 nephrectomy. These mice demonstrated a greater degree of cardiac fibrosis than the wild type. This study also supports the above-mentioned role of MBG by demonstrating MBGinduced translocation of PKC, resulting in decreases in Fli-1 expression.

Bro et al. [75] have also exploited the mouse genome, by using apolipoprotein E deficient C57BL/6 mice, which are resistant to the development of hypertension post-subtotal nephrectomy, to study the effect of uraemia on the heart, independently of blood pressure. These mice did not develop any defects in cardiac structure or function postnephrectomy. However, Siedlecki et al. [76] demonstrated that nephrectomised $129 / \mathrm{SvJ}$ mice developed histological signs of uraemic cardiomyopathy without hypertension or volume overload.

\section{VASCULAR CALCIFICATION IN CHRONIC RENAL FAILURE}

Mouse models, as well as rat models, have been extensively used in the study of vascular calcification in chronic renal failure [77]. Calcification of uraemic vessels is common, and associated with a greater cardiovascular mortality [78]. A review of animal models of vascular calcification already exists [77], thus, the present review focuses briefly on animal models of uraemic vascular calcification.

Knockout mouse models have been used to study the pathophysiology of vascular calcification. For example, studies have been used to demonstrate that low-densitylipoprotein (LDL)-receptor knockout and a high cholesterol diet results in increased calcification of the intima and media of the aorta $[79,80]$. The 5/6 nephrectomy rat model has been used in pharmacological studies, in order to demonstrate the effects of calcitriol on vascular calcification in uraemia [78], and to study the potential use of vitamin D analogues such as 22-oxacalcitriol (OCT). For example, Hirata et al. [81] demonstrated that OCT was effective in suppressing PTH in uraemic Sprague-Dawley rats, while producing less vascular calcification. Tamura et al. [82] used the same model in Wistar-Imamichi rats to show that the bisphosphonate etidronate prevents calcification of the aorta in renal failure.

\section{DE NOVO CARDIOMYOPATHY AFTER RENAL TRANSPLANTATION}

Although renal transplants have been shown to ameliorate cardiovascular disease progression [83], human studies have highlighted a problem of new congestive cardiac failure in many patients post-renal transplantation [84, 85]. Few animal models have been used to provide insight into the pathological processes involved. Baumann et al. [2] orthotopically transplanted kidneys, under ciclosporin immunosuppression, from Fisher rats into Lewis rats, which had their native kidneys removed. This resulted in increased left ventricular mass at 24 weeks post-transplant; this effect was dampened in transplanted rats given the angiotensin receptor blocker candesartan. However, controls consisted of untreated rats, i.e. rats not subjected to surgery or to pharmacological agents. Although it would appear that this model offers an opportunity to study the so-called transplantationinduced cardiomyopathy, more convincing control groups are needed.

\section{CONCLUSIONS}

Experimental models have played a crucial role in the study of the complex interplay between the heart and the kidney in chronic renal disease. In view of the numerous differences in animal and human anatomy, physiology and pathology, the results of these experiments should be interpreted with caution, but in some areas, these studies have led directly to advances in therapeutics. Conditions such as uraemic cardiomyopathy and transplantation-induced cardiomyopathy are still poorly understood, and it is clear that animal models will continue to provide hitherto unforeseen insights into their pathophysiology.
ABBREVIATIONS

$\begin{array}{ll}\text { ACE } & =\text { Angiotensin converting enzyme } \\ \text { BFGF } & \text { Basic fibroblast growth factor } \\ \text { ERK } & =\text { Extracellular signal regulated kinase } \\ \text { Fli-1 } & \text { Friend leukaemia integration-1 transcription } \\ \text { GH } & =\text { Growth hormone } \\ \text { LDL } & =\text { low-density-lipoprotein } \\ \text { MBG } & =\text { Marinobufagenin } \\ \text { NO } & =\text { Nitric oxide } \\ \text { PTH } & =\text { Parathyroid hormone } \\ \text { PKC } & =\text { Protein kinase C } \\ \text { RAS } & =\text { Renin-angiotensin system } \\ \text { TGF- } \beta & =\text { Transforming growth factor-beta } \\ \text { VEGF } & =\text { Vascular endothelial growth factor } \\ \text { OCT } & =22 \text {-oxacalcitriol }\end{array}$




\section{ACKNOWLEDGEMENTS}

I am immensely grateful to Professor Alexander J Howie for his encouragement and helpful feedback regarding this work.

\section{REFERENCES}

[1] Amann K, Ritz E. The heart in renal failure: Morphological changes of the myocardium - new insights. J Clin Basic Cardiol 2001; 4: 109-13.

[2] Baumann M, Chang J, Thürmel K, et al. Fisher-Lewis kidney transplantation model as a tool for investigation of transplantationinduced cardiomyopathy. Transplant Proc 2009; 41: 2612-5.

[3] Raine AEG, Seymour A-ML, Roberts AFC, Radda GK, Ledingham JGG. Impairment of cardiac function and energetics in experimental renal failure. J Clin Invest 1993; 92: 2934-40.

[4] Pinto YM, Paul M, Ganten D. Lessons from rat models of hypertension: From Goldblatt to genetic engineering. Cardiovasc Res 1998; 39: 77-88.

[5] Wolfensohn S, Lloyd M. Handbook of laboratory animal management and welfare. 3rd ed. Oxford: Blackwell 2003.

[6] Hasenfuss G. Animal models of human cardiovascular disease, heart failure and hypertrophy. Cardiovasc Res 1998; 39: 60-76.

[7] Doggrell SA, Brown L. Rat models of hypertension, cardiac hypertrophy and failure. Cardiovasc Res 1998; 39: 90-105.

[8] Lerman LO, Chade AR, Sica V, Napoli C. Animal models of hypertension: An overview. J Lab Clin Med 2005; 146:160-73.

[9] Glodny B, Glodny DE. John Loesch, discoverer of renovascular hypertension, and Harry Goldblatt: Two great pioneers in circulation research. Ann Intern Med 2006; 144: 286-95.

[10] Bermann LB. Harry Goldblatt: 1891-1977. JAMA 1977; 238: 1846.

[11] Goldbatt H, Lynch J, Hanzal RF, Summerville WW. Studies on experimental hypertension: I. The production of persistent elevation of systolic blood pressure by means of renal ischemia. J Exp Med 1934; 59: 347-79.

[12] Goldblatt H. Studies on experimental hypertension: III. The production of persistent hypertension in monkeys (macaque) by renal ischemia. J Exp Med 1937; 65: 671-5.

[13] Goldblatt H, Kahn JR, Hanzal RF. Studies on experimental hypertension: IX. The effect on blood pressure of constriction of the abdominal aorta above and below the site of origin of both main renal arteries. J Exp Med 1939; 69: 649-74.

[14] Goldblatt H, Kahn JR, Lewis HA. Studies on experimental hypertension: XIX. The production of persistent hypertension in sheep and goats. J Exp Med 1943; 77: 297-307.

[15] Goldblatt H. Experimental renal hypertension: mechanisms of production and maintenance. Circulation 1958; 17: 642-7.

[16] Goldblatt H. Hypertension due to renal ischemia. Bull N Y Acad Med 1964; 40: 745-58.

[17] Pickering GW, Prinzmetal M. Experimental hypertension of renal origin in the rabbit. Clin Sci 1938; 3: 357.

[18] Wilson C, Byron FB. Renal changes in malignant hypertension: Experimental evidence. Lancet 1939; i: 136-9.

[19] Leenen FHH, De Jong W. A solid silver clip for induction of predictable levels of renal hypertension in the rat. J Appl Physiol 1971; 31: 142-4

[20] Capasso JM, Palackal T, Olivetti G, Anversa P. Left ventricular failure induced by long-term hypertension in rats. Circ Res 1990; 66: 1400-12.

[21] Brilla CG, Pick R, Tan LB, Janicki JS, Weber KT. Remodeling of the rat right and left ventricles in experimental hypertension. Circ Res 1990; 67: 1355-64.

[22] Dobrian AD, Schriver SD, Prewitt RL. Role of angiotensin II and free radicals in blood pressure regulation in a rat model of renal hypertension. Hypertension 2001; 38: 361-6.

[23] Johns C, Gavras I, Handy DE, Salomao A, Gavras H. Models of experimental hypertension in mice. Hypertension 1996; 28: 1064-9.

[24] Wiesel P, Mazzolai L, Nussberger J, Pedrazzini T. Two-kidney, one clip and one-kidney, one clip hypertension in mice. Hypertension 1997; 29: 1025-30.

[25] Lerman LO, Nath KA, Rodriguez-Porcel M, et al. Increased oxidative stress in experimental renovascular hypertension. Hypertension 2001; 37: 541-6.
[26] Page IH. Production of persistent arterial hypertension by cellophane perinephritis. JAMA 1939; 113: 2046-8.

[27] Grollman A. A simplified procedure for inducing chronic renal hypertension in the mammal. Proc Soc Exp Biol Med 1944; 57: 102-4.

[28] Siragy HM, Carey RM. Protective role of the angiotensin AT2 receptor in a renal wrap hypertension model. Hypertension 1999; 33: $1237-42$.

[29] Munagala VK, Hart CYT, Burnett Jr JC, Meyer DM, Redfield MM. Ventricular structure and function in aged dogs with renal hypertension: a model of experimental diastolic heart failure. Circulation 2005; 111: 1128-35.

[30] Rieder MJ, Roman RJ, Greene AS. Reversal of microvascular rarefaction and reduced renal mass hypertension. Hypertension 1997; 30: 120-7.

[31] Katki KA, Supowit SC, DiPette DJ. Substance P in subtotal nephrectomy-salt hypertension. Hypertension 2002; 39: 389-93.

[32] Gross M-L, Ritz E. Hypertrophy and fibrosis in the cardiomyopathy of uremia - beyond coronary heart disease. Semin Dialysis 2008; 21: 308-18.

[33] Fabris B, Carretta R, Fischetti F, et al. Contribution of systemic blood pressure to myocardial remodeling in uremic rats. Hypertension 1995; 26: 321-6.

[34] Amann K, Gassmann P, Buzello M, et al. Effects of ACE inhibition and bradykinin antagonism on cardiovascular changes in uremic rats. Kidney Int 2000; 58: 153-61.

[35] Perez-Ruiz L, Ros-Lopez S, Cardus A, Fernandez E, Valdivielso JM. A forgotten method to induce experimental chronic renal failure in the rat by ligation of the renal parenchyma. Nephron Exp Nephrol 2006; 103: 126-30.

[36] Conti M, Renaud IM, Poirier B, et al. High levels of myocardial antioxidant defense in aging nondiabetic normotensive Zucker obese rats. Am J Physiol Regul Integr Comp Physiol 2004; 286: R793-800.

[37] Rambausek M, Ritz E, Mall G, Mehls O, Katus H. Myocardial hypertrophy in rats with renal insufficiency. Kidney Int 1985; 28 775-82.

[38] Grawitz P, Israel O. Experimentelle Untersuchungen Uber den Zusammenhang zwischen Nierenerkrankungen und Herzhypertrophie. Virchows Arch Path Anat 1879; 77: 315-46.

[39] McMahon AC, Greenwald SE, Dodd SM, Hurst MJ, Raine AEG. Prolonged calcium transients and myocardial remodelling in early experimental uraemia. Nephrol Dial Transplant 2002; 17 : 759-64.

[40] Mall G, Rambausek M, Neumeister A, Kollmar S, Vetterlein F, Ritz E. Myocardial interstitial fibrosis in experimental uremia implications for cardiac compliance. Kidney Int 1988; 33: 804-11.

[41] Amann K, Wiet G, Zimmer G, Gretz N, Ritz E, Mall G. Reduced capillary density in the myocardium of uremic rats - a stereological study. Kidney Int 1992; 42: 1079-85.

[42] Amann K, Neusüss R, Ritz E, Irzyniec T, Wiest G, Mall G. Changes of vascular architecture independent of blood pressure in experimental uremia. Am J Hypertens 1995; 8: 409-17.

[43] Törnig J, Gross M-L, Simonaviciene A, Mall G, Ritz E, Amann K. Hypertrophy of intramyocardial arteriolar smooth muscle cells in experimental renal failure. J Am Soc Nephrol 1999; 10: 77-83.

[44] Törnig J, Amann K, Ritz E, Nichols C, Zeler M, Mall G. Arteriolar wall thickening, capillary rarefaction and interstitial fibrosis in the heart of rats with renal failure: The effects of ramipril, nifedipine and moxonidine. J Am Soc Nephrol 1996; 7: 667-75.

[45] Amann K, Neimeier KA, Schwarz U, et al. Rats with moderate renal failure show capillary deficit in heart but not skeletal muscle. Am J Kidney Dis 1997; 30: 382-8.

[46] Donohoe P, Hendry BM, Walgama OV, et al. An altered repolarizing potassium current in rat cardiac myocytes after subtotal nephrectomy. J Am Soc Nephrol 2000; 11: 1589-99.

[47] Mann JF, Jakobs KH, Riedel J, Ritz E. Reduced chronotropic responsiveness of the heart in experimental uremia. Am J Physiol Heart Circ Physiol 1986; 250: H846-52.

[48] Dhein S, Röhnert P, Markau S, et al. Cardiac beta-adrenoceptors in chronic uremia: Studies in humans and rats. J Am Coll Cardiol 2000; 36: 608-17.

[49] Weisensee D, Löw-Friedrich I, Riehle M, Bereiter-Hahn J, Schloeppe W. In vitro approach to 'uremic cardiomyopathy' Nephron 1993; 65: 392-400. 
[50] Reddy V, Bhandari S, Seymour A-ML. Myocardial function, energy provision, and carnitine deficiency in experimental uremia. J Am Soc Nephrol 2007; 18: 84-92.

[51] Rostand SG, Drüeke TB. Parathyroid hormone, vitamin D, and cardiovascular disease in chronic renal failure. Kidney Int 1999; 56: 383-92.

[52] Massry SG. Parathyroid hormone and uremic myocardiopathy. Contrib Nephrol 1984; 41: 231-39.

[53] Smogorzewski M, Zayed M, Zhang YB, Roe J, Massry SG. Parathyroid hormone increases cytosolic calcium concentration in adult rat cardiac myocytes. Am J Physiol Heart Circ Physiol 1993; 264: H1998-2006.

[54] Smogorzewski M, Tian J, Massry SG. Down-regulation of PTHPTHrP receptor of heart in CRF: role of $\left[\mathrm{Ca}^{2+}\right]_{\mathrm{i}}$. Kidney Int 1995; 47: 1182-6.

[55] Wang R, Wu L, Karpinski E, Pang PK. The changes in contractile status of single vascular smooth muscle cells and ventricular cells induced by bPTH-(1-34). Life Sci 1993; 52: 793-801.

[56] Amann K, Ritz E, Wiest G, Klaus G, Mall G. A role of parathyroid hormone for the activation of cardiac fibroblasts in uremia. J Am Soc Nephrol 1994; 4: 1814-9.

[57] Amann K, Törnig J, Flechtenmacher C, Nabokov A, Mall G, Ritz E. Blood-pressure-independent wall thickening of intramyocardial arterioles in experimental uraemia: Evidence for a permissive action of PTH. Nephrol Dial Transplant 1995; 10: 2043-8.

[58] Ogata H, Ritz E, Odoni G, Amann K, Orth SR. Beneficial effects of calcimimetics on progression of renal failure and cardiovascular risk factors. J Am Soc Nephrol 2003; 14: 959-67.

[59] Slinin Y, Foley RN, Collins AJ. Calcium, phosphorus, parathyroid hormone, and cardiovascular disease in hemodialysis patients: the USRDS waves 1,3, and 4 study. J Am Soc Nephrol 2005; 16: 178893.

[60] Suzuki H, Schaefer L, Ling H, et al. Prevention of cardiac hypertrophy in experimental chronic renal failure by long-term ace inhibitor administration: Potential role of lysosomal proteinases. Am J Nephrol 1995; 15: 129-36.

[61] Amann K, Miltenberger-Miltenyi G, Simonoviciene A, Koch A, Orth S, Ritz E. Remodeling of resistance arteries in renal failure: effect of endothelin receptor blockade. J Am Soc Nephrol 2001; 12: $2040-50$.

[62] Nabokov AV, Amann K, Wessels S, Münter K, Wagner J, Ritz E. Endothelin receptor antagonists influence cardiovascular morphology in uremic rats. Kidney Int 1999; 55: 512-9.

[63] Takahashi H, Takeishi Y, Miyamoto T, et al. Protein kinase C and extracellular signal regulated kinase are involved in cardiac hypertrophy of rats with progressive renal injury. Eur J Clin Invest 2004; 34: 85-93.

[64] Takahashi H, Takeishi Y, Arimoto T, et al. Pitavastatin inhibits cardiac hypertrophy in a rat model of progressive renal injury. $\mathrm{J}$ Cardiovasc Pharm 2005; 46: 487-93.

[65] Noris M, Benigni A, Boccardo P et al. Enhanced nitric oxide synthesis in uremia: Implications for platelet dysfunction and dialysis hypotension. Kidney Int 1993; 44: 445-50.

[66] Kalk P, Godes M, Relle K, et al. NO-independent activation of soluble guanylate cyclase prevents disease progression in rats with 5/6 nephrectomy. Br J Pharmacol 2006; 148: 853-9.

[67] Michea L, Villagrán A, Urzúa A, et al. Mineralocorticoid receptor antagonism attenuates cardiac hypertrophy and prevents oxidative stress in uremic rats. Hypertension 2008; 52: 295-300.
[68] Bai Y, Sigala W, Adams GR, Vaziri ND. Effect of exercise on cardiac tissue oxidative and inflammatory mediators in chronic kidney disease. Am J Nephrol 2009; 29: 213-21.

[69] Rabkin R, Awaad I, Chen Y, et al. Low-dose growth hormone is cardioprotective in uremia. J Am Soc Nephrol 2008; 19: 1774-83.

[70] Kennedy DJ, Vetteh S, Periyasamy SM, et al. Central role for the cardiotonic steroid marinobufagenin in the pathogenesis of experimental uremic cardiomyopathy. Hypertension 2006; 47: 488-95.

[71] Elkareh J, Kennedy DJ, Yashaswi B, et al. Marinobufagenin stimulates fibroblast collagen production and causes fibrosis in uremic cardiomyopathy. Hypertension 2007; 49: 215-24.

[72] Kennedy D, Omran E, Periyasamy SM, et al. Effect of chronic renal failure on cardiac contractile function, calcium cycling, and gene expression of proteins important for calcium homeostasis in the rat. J Am Soc Nephrol 2003; 14: 90-7.

[73] Kennedy DJ, Elkareh J, Shidyak A, et al. Partial nephrectomy as a model for uremic cardiomyopathy in the mouse. Am J Physiol Renal Physiol 2008; 294: F450-54.

[74] Elkareh J, Periyasamy SM, Shidyak A, et al. Marinobufagenin induces increases in procollagen expression in a process involving protein kinase $\mathrm{C}$ and Fli-1: Implications for uremic cardiomyopathy. Am J Physiol Renal Physiol 2009; 296: F1219-26.

[75] Bro S, Bollano E, Brüel A, Olgaard K, Nielsen LB. Cardiac structure and function in a mouse model of uraemia without hypertension. Scand J Clin Lab Invest 2008; 68: 660-6.

[76] Siedlecki AM, Jin X, Muslin AJ. Uremic cardiac hypertrophy is reversed by rapamycin but not by lowering of blood pressure. Kidney Int 2009; 75: 800-8.

[77] Wallin R, Wajih N, Greenwood GT, Sane DC. Arterial calcification: A review of mechanisms, animal models, and the prospects for therapy. Med Res Rev 2001; 21: 274-301.

[78] Mizobuchi M, Ogata H, Koiwa F, Kinugasa E, Akizawa T. Vitamin D and vascular calcification in chronic kidney disease. Bone 2009; 45: S26-9.

[79] Davies MR, Lund RJ, Hruska KA. BMP-7 is an efficacious treatment of vascular calcification in a murine model of atherosclerosis and chronic renal failure. J Am Soc Nephrol 2003; 14: 1559-67.

[80] Moe SM, Chen NX. Pathophysiology of vascular calcification in chronic kidney disease. Circ Res 2004; 95: 560-7.

[81] Hirata M, Katsumata K, Endo K, Fukushima N, Ohkawa H, Fukagawa M. In subtotally nephrectomized rats 22-oxacalcitriol suppresses parathyroid hormone with less risk of cardiovascular calcification or deterioration of residual renal function than 1,25(OH)2 vitamin D3. Nephrol Dial Transplant 2003; 18: 1770-6.

[82] Tamura K, Suzukia Y, Matsushita M et al. Prevention of aortic calcification by etidronate in the renal failure rat model. Eur $\mathrm{J}$ Pharmacol 2007; 558: 159-66.

[83] Meier-Kriesche H-U, Schold JD, Srinivas TR, Reed A, Kaplan B. Kidney transplantation halts cardiovascular disease progression in patients with end-stage renal disease. Am J Transplant 2004; 4 : $1662-8$.

[84] Rigatto C, Parfrey P, Foley R, Negrijn C, Tribula C, Jeggery J. Congestive heart failure in renal transplant recipients: risk factors, outcomes, and relationship with ischemic heart disease. J Am Soc Nephrol 2002; 13: 1084-90.

[85] Lentine KL, Schnitzler MA, Abbott KC, et al. De novo congestive heart failure after kidney transplantation: A common condition with poor prognostic implications. Am J Kidney Dis 2005; 46: 72033. 